\title{
ECP-SOCIAL: uma proposta de avaliação da performance social para negócios sustentáveis
}

\section{ECP-SOCIAL: a proposal of a corporate social performance evaluation for sustainable bunisess}

\author{
Carla Regina Pasa Gómez ${ }^{l}$ \\ Leonardo Augusto Gómez Castillo²
}

\begin{abstract}
Resumo
Este artigo apresenta o modelo ECP-Social, cuja proposta é identificar a performance social empresarial a partir de um framework de indicadores. A premissa de que a performance social é resultante de um comportamento empresarial frente a pressões da estrutura da indústria e de choques externos a ela delineia o modelo, que conta ainda com uma ferramenta para a sua operacionalização, por meio da qual se identifica o comportamento social, confrontado que, na seqüência, com a estrutura da indústria, gerando o perfil social empresarial. O modelo permite colherem-se informações que permitem a tomada de decisão em relação ao gerenciamento do impacto social.
\end{abstract}

Palavras-chave: Responsabilidade social. Modelo de avaliação da performance social empresarial.

\section{Abstract}

This paper presents the ECP-Social model, whose proposal is to identify corporate social performance by using a framework of indicators, based on the idea that corporate social performance is the result of corporate behavior against industry structure pressures and external forces. For the operationalization of the ECP-Social, a tool is used to identify corporate social behavior, and the result of this process is confronted with the industry structure in order to obtain the corporate social profile. The model allows to collect important information to support the decision making process for the management of social impact.

Keywords: Corporate Social Responsibility, Model for Corporate Social Performance Evaluation.

\section{Introdução}

As estratégias em responsabilidade social (r.s.) vêm sendo amplamente discutidas nos meios acadêmicos e profissionais como uma das variáveis determinantes para a sustentabilidade dos negócios, tanto em âmbito de países desenvolvidos como de países em desenvolvimento.

O crescimento da responsabilidade social como um aspecto da sociedade contemporânea origina-se como extensão dos eventos que vêm ocorrendo para promover uma eqüidade entre aspectos econômicos, sociais e ambientais, e em virtude de novas expectativas e demandas da sociedade, tão latentes em países menos desenvolvidos.

\footnotetext{
1 Doutora em Engenharia de Produção - UFSC - Professora da Universidade Federal de Pernambuco - Endereço: PROPAD/DCA Rua Prof. Moraes Rego, 1235, Cidade Universitária, Recife, PE, Brasil - CEP: 50670-901 - Email: carlapasa@ @otmail.com

2 Doutor em Human and Environmental Studies - Kyoto University, Japão. Professor da Universidade Federal de Pernambuco - Endereço: PROPAD/DCA Rua Prof.

Moraes Rego, 1235, Cidade Universitária, Recife, PE, Brasil CEP: 50670-901 - Email: prismatica@yahoo.com
}

Artigo recebido em janeiro de 2006 e aceito para publicação em março de 2006 
Porém, no momento de estabelecer suas ações em responsabilidade social, a grande maioria das empresas o faz sem um foco planejado, o que as leva a investir em várias áreas sociais e, em muitos casos, a não atingir o objetivo de minimizar os impactos sobre seus afetados e interessados (a.\&i.). Tal fato demonstra que a gestão do social ainda carece de melhoria. Para retratar essa situação, pode-se citar o caso da Petrobrás ( REVISTA EXAME, 2003), que, até o ano de 2002, vinha investindo em mais de 300 projetos sociais sem uma avaliação prévia acerca do impacto dessas ações sobre seus a.\&i. e do resultado para a empresa.

Esse exemplo leva ao seguinte questionamento: se, na hora de produzir, as empresas acompanham cuidadosamente a evolução dos investimentos para assegurar o retorno, por que não fazem o mesmo quando investem no social?. Como podem saber se o que estão doando está de fato promovendo transformações? E, ainda, qual o resultado alcançado com a aplicação desse capital?

Segundo o IPEA (Instituto de Pesquisas Econômicas Aplicadas), (REVISTA EXAME, 2003), a ausência de avaliação de resultados dos investimentos sociais é um dos principais obstáculos ao desenvolvimento da responsabilidade social corporativa. Em pesquisa realizada no ano de 2002, o IPEA identificou que apenas $2 \%$ dos investidores privados controlavam a destinação dos recursos, monitoravam e verificavam se suas ações implicavam melhoria nos impactos sociais. Outros $86 \%$ afirmaram que só disponibilizavam verbas, e o restante (12\%) acompanhava os trabalhos informalmente, sem metodologias precisas.

Portanto, verifica-se uma contradição empresarial, haja vista as empresas dependerem da avaliação de resultados para direcionar suas estratégias e tomar decisões. Na prática empresarial, quando uma empresa lança um produto novo no mercado, logo se identificam indicadores que mensurem seu desempenho, sendo assim, o mesmo deveria ocorrer com investimentos sociais.

A falta de avaliação da performance social empresarial, segundo Fischer (REVISTA EXAME, 2003), pode acarretar também a falta de credibilidade das ações sociais e, consequientemente, um resultado negativo de tais práticas.

Por isso, acredita-se que a avaliação dos resultados empresariais deva ser parte do gerenciamento social, ainda mais considerando que as estratégias empresariais são dinâmicas e necessitam de acompanhamento e monitoramento constantes. Diante desta problemática, este artigo tem como objetivo apresentar o modelo ECP-Social (Estrutura, Conduta e Performance-Social) como um novo modelo de avaliação da performance social para negócios sustentáveis.

\section{Metodologia}

\section{Delineamento metodológico}

Os procedimentos metodológicos utilizados seguem a orientação de Silva e Menezes (2001). A pesquisa caracteriza-se como aplicada, do ponto de vista de sua natureza; como qualitativa, quanto à forma de abordagem do problema; e descritiva, quanto aos seus objetivos. Os procedimentos técnicos constituíram-se de pesquisa bibliográfica, uma vez que sua elaboração se deu a partir de material já publicado, constituído principalmente de livros e de artigos de periódicos e de material disponibilizado pela Internet.

\section{Delineamento metodológico do modelo ECP-Social}

A construção do framework do modelo ECP-Social foi orientada pelo modelo ECP de Scherer e Ross (1990), no qual se observou com mais atenção os elementos de estrutura de mercado; e pelo modelo ECP-Ambiental (ABREU, 2001), em que se observou com mais atenção os elementos de conduta empresarial. Também se recorreu aos modelos de Carroll (1979) e Wood (1991) para a sustentação teórica.

O framework do modelo ECP-Social está dividido em: (a) categorias (Estrutura, Conduta e Performance) compostas por (b) dimensões subdivididas em (c) grupos de elementos que, por sua vez, são compostos por (d) indicadores chamados de critérios de análise, cujo objetivo é mensurar individualmente as características de cada um deles. 
Alguns dados de performance são coletados em forma de dados absolutos e podem ser expressos em unidade financeira ou medida física, para um dado período de tempo. Este tipo de dados prevê informações sobre o tamanho do impacto, o valor ou a realização de uma determinada ação. São utilizados para identificar indicadores de performance como, por exemplo, número de acidentes de trabalho.

Os dados normativos são resultados de comparações entre dados absolutos do mesmo ou de diferentes tipos. Indicadores normativos prevêem informações da eficiência de uma atividade, ou da intensidade do impacto ou da qualidade de um valor ou de uma realização. Podem ser utilizados para tornar explícitos os elementos de relações humanas como o exercício da cidadania.

Por isso, a inter-relação de dados absolutos e normalizados torna os dados de performance compreensíveis e mais úteis à tomada de decisão. Este relacionamento também facilita a discussão, interpretação e aprendizado de ambos, provedores e usuários, acerca das informações sobre a performance social. Esta inter-relação pode ser expressa de várias formas: (a) com o rastreamento do desenvolvimento organizacional ao longo do tempo (ex.: relacionando os dados de diferentes anos, ou relacionando os dados da meta com o ano-base); (b) com o estabelecimento de uma relação entre os dados de diferentes categorias ou aspectos (ex.: relacionando a abrangência do impacto social gerado pela empresa versus a capacidade e habilidade de ação dela); (c) com a normalização dos dados para o tamanho da empresa ou das operações, tendo como objetivo torná-los comparáveis.

\section{Revisão teórica}

Existe um consenso emergente entre pesquisadores da área (CARROLL e BUCHHOLTZ, 2003; WOOD, 1991; e outros) de que o escopo das responsabilidades de uma empresa no campo social não está confinado a atividades filantrópicas. Ele se estende do grau de compreensão das suas responsabilidades legais às práticas discricionárias.

Quando se fala em práticas sociais, não se quer dizer que a empresa deva abandonar seu objetivo de gerar lucro e rentabilidade ou pretender ser menos lucrativa do que aquelas que não promovem tais práticas empresariais. Responsabilidade social requer que as empresas promovam um balanço dos resultados econômicos com uma distribuição eqüidistante entre os resultados dos seus impactos ambientais e sociais (TAKALA, 1996).

Assim, com o objetivo de avaliar os impactos de suas atividades, comunicá-los para a sociedade, obter feedback dos a.\&i e melhoria na vantagem competitiva, as empresas, aos poucos, começam a utilizar tais conceitos.

Nessa direção, a performance social se propõe a avaliar ou valorar o comportamento corporativo a partir de uma perspectiva externa, considerando não apenas a existência de resultados econômicos, mas também sociais. Segundo Carroll $(1979,1999)$ e Carroll e Buchholtz (2003), a performance social está diretamente relacionada à avaliação das responsabilidades sociais do negócio, da identificação de aspectos sociais e da filosofia escolhida para as respostas sociais.

Em busca da avaliação da performance social, Wood (1991) sugere que as empresas examinem tanto o grau de integração dos princípios de responsabilidade social e as ações que motivam a empresa a investir nessa área, como também o grau com que a mesma responde às demandas e aos impactos sociais. Deve-se, ainda, examinar a existência e a natureza das políticas e programas designados para o gerenciamento do relacionamento com a sociedade e os impactos das ações.

O principal entendimento a respeito da performance social é que ela não é um resultado distinto dos demais, econômicos e ambientais, e tampouco isolado (CARROL, 1979, 1999; CARROLL e BUCHHOLTZ, 2003; WARTICK e COCHRAN, 1985; WOOD, 1991, 1995; SWANSON, 1995, 1999). 


\section{O Modelo ECP-Social}

A construção do modelo ECP-Social (Figura 1) tem como princípio básico que a performance social empresarial é o reflexo das ações e reações empresariais frente à competição, decorrentes dos seus padrões de conduta social, que, por sua vez, dependem reciprocamente da estrutura de mercado em que a empresa está inserida, considerando-se que ela atua em um sistema aberto, no qual interage com os demais elementos do ambiente externo, influenciando-os e recebendo suas influências; e ainda que essa relação não é linear e que a influência de uma variável sobre a outra ocorre em via dupla. Além desses elementos, o modelo ECP-Social considera a influência dos choques externos, que são caracterizados pela ausência de periodicidade e pela capacidade de gerar influências sobre a estrutura, conduta e performance.

Figura 1: Modelo ECP-Social.

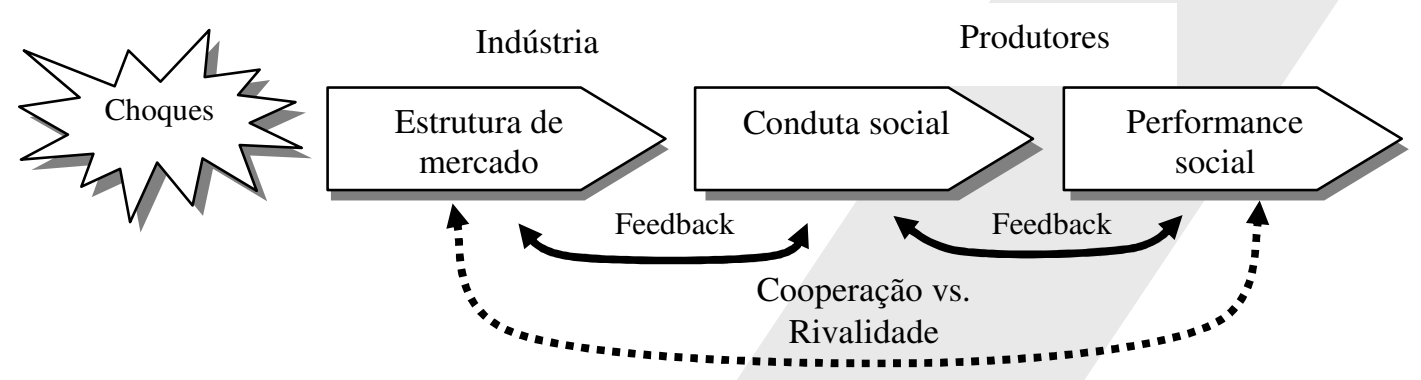

O framework do modelo ECP-Social (Figura 2) apresenta elementos de estrutura e de conduta e indicadores de performance social empresarial a partir dos processos de reações empresariais, contemplando aspectos relacionados ao impacto social interno e externo. 


\section{Figura 2: Framework do modelo ECP-Social.}

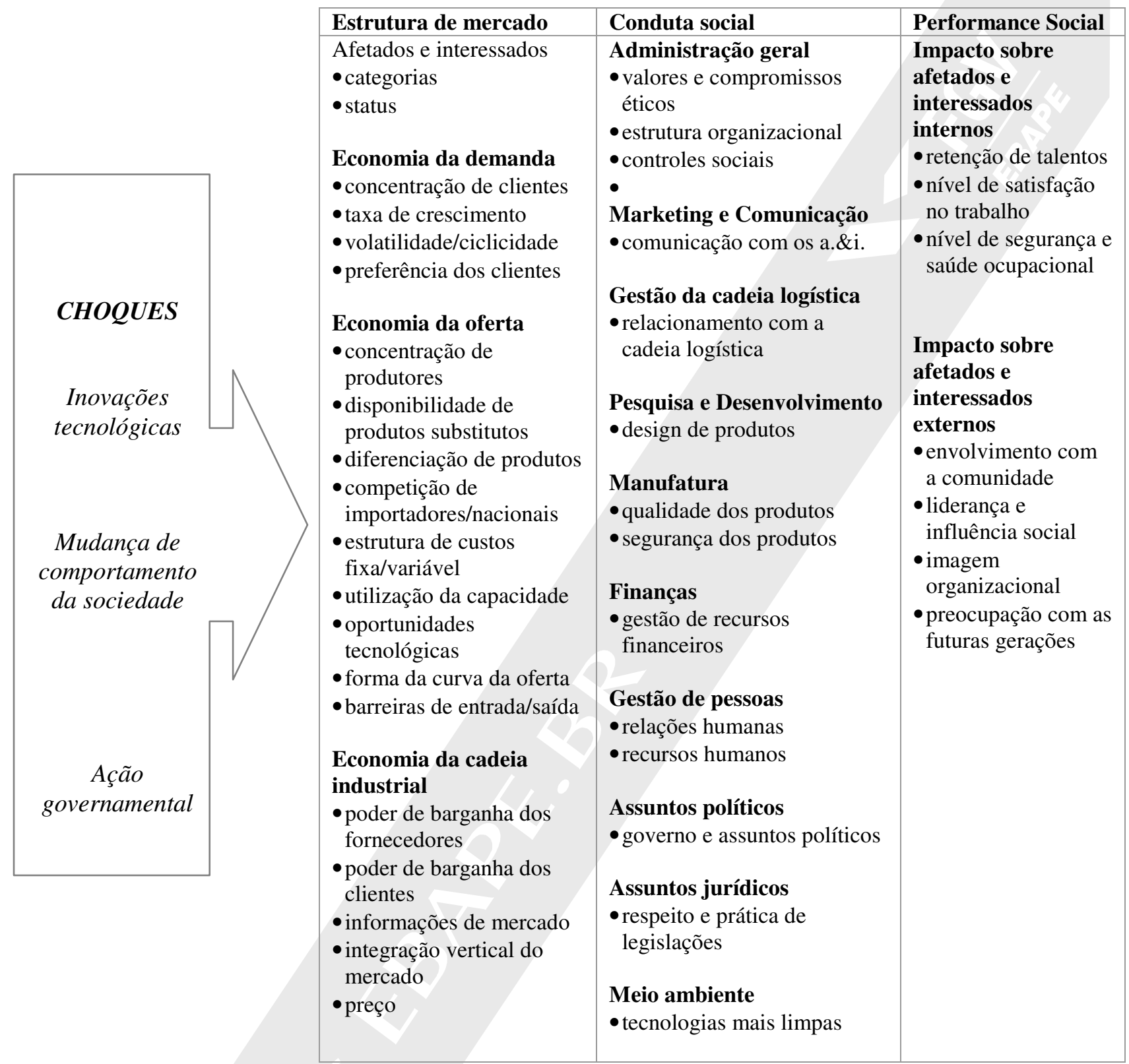

\section{Indicadores de estrutura de mercado}

Para a elaboração do modelo ECP-Social, considerou-se que a categoria de estrutura de mercado relaciona-se à dimensão de oferta, demanda e economia da cadeia industrial apresentada pelo modelo ECP de Scherer e Ross (1990), e que estes, geralmente, não apresentam diferenças significativas de uma estrutura da indústria do ponto de vista econômico ou social; por isso, tais elementos foram mantidos.

Porém, percebeu-se que alguns dos elementos permitem interpretação social, os quais são apresentados no Quadro 1. Além disso, acrescentou-se à categoria "estrutura de mercado" a dimensão "afetados e interessados". 


\section{Quadro 1: Dimensões e elementos da categoria de estrutura de mercado com interpretação social.}

\begin{tabular}{|c|c|c|c|}
\hline Categoria & Dimensão & Elemento & Critério de análise \\
\hline \multirow{5}{*}{$\begin{array}{l}\text { Estrutura } \\
\text { de } \\
\text { mercado }\end{array}$} & \multirow{2}{*}{$\begin{array}{l}\text { Afetados } \\
\text { e } \\
\text { interessados }\end{array}$} & Categorias & $\begin{array}{l}\text { A.\&i. de núcleo } \\
\text { A.\&i. estratégicos } \\
\text { A.\&i. de ambiente }\end{array}$ \\
\hline & & Status & $\begin{array}{l}\text { Natureza da relação } \\
\text { Poder de influência/capacidade de produzir (re)ações de } \\
\text { efeito }\end{array}$ \\
\hline & $\begin{array}{l}\text { Economia de } \\
\text { demanda }\end{array}$ & Preferência dos clientes & $\begin{array}{l}\text { Ações sociais internas } \\
\text { Ações sociais externas }\end{array}$ \\
\hline & \multirow{2}{*}{$\begin{array}{l}\text { Economia } \\
\text { de oferta }\end{array}$} & $\begin{array}{l}\text { Competição de } \\
\text { importadores/nacionais }\end{array}$ & Quantidade de competidores nacionais e importadores \\
\hline & & $\begin{array}{l}\text { Barreiras de } \\
\text { entrada/saída }\end{array}$ & $\begin{array}{l}\text { Poder de organização da sociedade civil } \\
\text { Exigências de certificações ou práticas sociais }\end{array}$ \\
\hline
\end{tabular}

Sobre as dimensões "elemento" e "critério de análise" apresentadas no Quadro 1, faz-se necessário o esclarecimento da primeira dimensão. Isso porque se considera que uma indústria pode ser mais ou menos afetada em relação à organização de seus a.\&i., por isso, estes aparecem como dimensão que define e exerce influência sobre a estrutura da indústria. Para compreendê-la, foram definidos dois elementos: categorias de a.\&i. e status da relação entre eles e a empresa.

O elemento categoria de a.\&i. baseia-se nos resultados da II Conferência de Teoria dos Stakeholders, realizada em Toronto, em 1994, a qual apresentou três categorias: a.\&i. do núcleo, estratégicos e de ambiente.

Os a.\&i. considerados essenciais para a sobrevivência da empresa fazem parte do núcleo, enquanto os grupos de a.\&i. importantes para a organização em particular, porque apresentam oportunidades e riscos, são chamados de estratégicos. Além destes, os grupos de a.\&i. de ambiente são todos aqueles outros a.\&i. que não estão contemplados nas categorias anteriores, mas que não devem ser esquecidos.

A classificação dos a.\&i. nessas categorias depende de cada empresa. Algumas delas podem considerar como a.\&i. de núcleo os funcionários, acionistas, fornecedores, clientes, enquanto o governo, a mídia e a concorrência podem ser considerados a.\&i. estratégicos, e, ainda, como a.\&i. de ambiente, as ONGs, a comunidade e outros.

Isso significa dizer que a organização dos afetados e interessados (a.\&i.) e o poder que eles exercem sobre uma indústria podem exercer influências determinantes e importantes no processo de tomada de decisão e, conseqüentemente, na performance empresarial.

Porém, a influência dos a.\&i. sobre a conduta e a performance da empresa está condicionada ao status que os mesmos possuem nas suas relações com ela. Assim, o elemento status, baseado na teoria desenvolvida por Mitchell, Agle e Wood (1997), foi escolhido para identificar: (a) a natureza, o grau de legitimidade da relação dos a.\&i. com a empresa; (b) o poder de influência ou a capacidade que os mesmos possuem para fazer com que a empresa produza (re)ações de efeito diante dos impactos causados por ela; e (c) a capacidade de gerar urgência e agilidade das respostas por parte da empresa.

O que quer dizer que alguns grupos de a.\&i. poderão ter maior ou menor influência sobre a estrutura da indústria, pois a pressão destes sobre ela pode ser encarada como uma barreira de entrada/saída para competidores. Exemplificando, tem-se a capacidade de mobilidade da sociedade civil para deter um produto ou empresa, ou, ainda, de impedir a instalação de uma planta industrial com alto impacto ambiental.

A partir de uma interpretação conjunta dos elementos desta dimensão, percebe-se que a classificação dos a.\&i. em categorias está diretamente relacionada ao seu status. Ou seja, a denominação de quais a.\&i. são considerados de núcleo, estratégicos ou de ambiente liga-se a natureza, grau de legitimidade, poder e 
capacidade de gerar respostas urgentes sobre a empresa. Deve-se considerar, ainda, que os a.\&i. organizam-se de forma diferente para cada indústria.

Segundo Leite (1998), a estrutura refere-se às características de organização de um mercado, que parecem influenciar estrategicamente a natureza da competição dentro dele. Assim, esses indicadores permitem identificar a pressão sobre as estruturas da indústria, que será definida como alta, moderada ou fraca.

Uma pressão alta é aquela na qual os a.\&i. possuem um grande poder de influência sobre a empresa, com alta capacidade de produzir ações e reações de efeito. Além disso, uma grande quantidade de competidores nacionais e importadores - cujas ações sociais internas e externas são consideradas como preferenciais pelos clientes - cria padrões de exigências que são suportados pelo poder de organização da sociedade civil e da demanda de certificações ou práticas sociais, delineando o nível de pressão alta.

Já a pressão em nível moderado é aquela na qual os a.\&i. possuem uma força relativa sobre a empresa, ou seja, a capacidade de produzirem ações e reações de efeito é moderada. Assim também é moderada a quantidade de competidores nacionais e importadores, a sociedade civil é relativamente organizada e esporadicamente exige certificações ou práticas sociais, e no que diz respeito a clientes, estes esporadicamente consideram as ações sociais empresariais como elemento de pressão.

Por fim, uma pressão fraca é aquela em que a empresa quase não percebe a presença dos a.\&i., pois eles não possuem muito poder de influenciar ou capacidade de produzir reações e ações de efeito por parte da empresa. A estrutura da indústria não é influenciada significativamente pela quantidade de competidores nacionais e importadores, nem de suas ações sociais. Nesse caso, o poder de organização da sociedade civil e as exigências de certificações ou de práticas sociais são baixos e os clientes não consideram as ações sociais como vantagem competitiva das empresas.

\section{Elementos de conduta social}

As dimensões e elementos de conduta social referem-se ao comportamento que as empresas seguem para ajustar-se ou adequar-se ao mercado em que operam, representando o processo de decisão e as relações internas da empresa.

Para a elaboração destas dimensões e de seus elementos, com base no modelo ECP-Social, consideraram-se os indicadores utilizados pelo Instituto Ethos, o modelo de balanço social do IBASE, os indicadores do Global Report Initiative, as normas SA 8000 e AA 1000, o Global Compact e os indicadores do Dow Jones Sustainable Index e da BOVESPA.

Diante da complexidade e das inter-relações existentes nos diversos processos empresariais, durante a construção do framework do modelo ECP-Social, percebeu-se que vários elementos que definem a dimensão da conduta social fazem parte de outras dimensões, mesmo que de forma implícita.

Por exemplo, os elementos que demonstram a conduta empresarial em pesquisa e desenvolvimento, seleção de MP e ciclo de vida do produto, são refletidos em manufatura, qualidade e segurança dos produtos, e os relativos ao meio ambiente, tecnologias mais limpas são representados por programas de redução de resíduos e de educação ambiental. Considerando-se a continuidade dessas relações, percebe-se que os reflexos do elemento de manufatura, de segurança dos produtos, estão relacionados ao elemento de comunicação e marketing, através da comunicação dos danos potenciais dos produtos, e assim por diante.

Portanto, a categoria "conduta social" constitui-se de um conjunto de dimensões relacionadas ao processo de administração geral, marketing e comunicação, gestão da cadeia logística, pesquisa e desenvolvimento, manufatura, meio ambiente, finanças, gestão de pessoas, assuntos políticos e jurídicos (Quadro 2). 
Quadro 2: Dimensões e elementos da categoria de conduta social.

\begin{tabular}{|c|c|c|c|}
\hline Categoria & Dimensão & Elemento & Critério de análise \\
\hline \multirow{13}{*}{$\begin{array}{l}\text { Conduta } \\
\text { Social }\end{array}$} & \multirow{3}{*}{$\begin{array}{l}\text { Administração } \\
\text { Geral }\end{array}$} & $\begin{array}{l}\text { Valores e } \\
\text { compromissos } \\
\text { éticos }\end{array}$ & $\begin{array}{l}\text { Adoção e abrangência da declaração dos valores e do código } \\
\text { de ética } \\
\text { Forma de disseminação dos valores e princípios éticos }\end{array}$ \\
\hline & & $\begin{array}{l}\text { Estrutura } \\
\text { organizacional }\end{array}$ & $\begin{array}{l}\text { Evidência da prática da gestão participativa } \\
\text { Valorização da diversidade } \\
\text { Eliminação da discriminação }\end{array}$ \\
\hline & & Controles sociais & $\begin{array}{l}\text { Auditorias interna e externa } \\
\text { Normas e regras disciplinares }\end{array}$ \\
\hline & $\begin{array}{l}\text { Marketing e } \\
\text { comunicação }\end{array}$ & $\begin{array}{l}\text { Comunicação } \\
\text { com os a.\&i. }\end{array}$ & $\begin{array}{l}\text { Comunicação dos danos potenciais dos produtos } \\
\text { Seleção de elementos de promoção dos produtos, da marca e } \\
\text { da empresa } \\
\text { Divulgação dos processos e resultados sociais } \\
\text { Reclamações de consumidores/clientes }\end{array}$ \\
\hline & $\begin{array}{l}\text { Gestão da } \\
\text { cadeia } \\
\text { logística }\end{array}$ & $\begin{array}{l}\text { Relacionamento } \\
\text { com a cadeia } \\
\text { logística }\end{array}$ & $\begin{array}{l}\text { Exigência do cumprimento da CLT } \\
\text { Prática da Declaração dos Direitos Humanos } \\
\text { Eliminação do trabalho infantil }\end{array}$ \\
\hline & P.\&D. & $\begin{array}{l}\text { Design de } \\
\text { produtos }\end{array}$ & $\begin{array}{l}\text { Seleção de MP alternativas } \\
\text { Análise do ciclo de vida do produto }\end{array}$ \\
\hline & Manufatura & $\begin{array}{l}\text { Qualidade e } \\
\text { segurança dos } \\
\text { produtos }\end{array}$ & $\begin{array}{l}\text { Qualidade dos produtos } \\
\text { Segurança dos produtos }\end{array}$ \\
\hline & Meio ambiente & $\begin{array}{l}\text { Tecnologias } \\
\text { mais limpas }\end{array}$ & $\begin{array}{l}\text { Programas de redução de resíduos sólidos, efluentes líquidos } \\
\text { e emissões atmosféricas } \\
\text { Educação ambiental }\end{array}$ \\
\hline & Finanças & $\begin{array}{l}\text { Gestão de } \\
\text { recursos } \\
\text { financeiros }\end{array}$ & $\begin{array}{l}\text { Boa governança corporativa } \\
\text { Política de investimentos sociais }\end{array}$ \\
\hline & & $\begin{array}{l}\text { Relações } \\
\text { humanas }\end{array}$ & $\begin{array}{l}\text { Relação com os sindicatos e liberdade de associação } \\
\text { Comportamento frente a demissões e aposentadoria } \\
\text { Exercício do voluntariado }\end{array}$ \\
\hline & $\begin{array}{l}\text { Gestão de } \\
\text { pessoas }\end{array}$ & $\begin{array}{l}\text { Recursos } \\
\text { humanos }\end{array}$ & $\begin{array}{l}\text { Participação nos resultados } \\
\text { Prevenção de doenças ocupacionais } \\
\text { Existência de programas de desenvolvimento e capacitação } \\
\text { profissional e pessoal } \\
\text { Programas de benefícios }\end{array}$ \\
\hline & $\begin{array}{l}\text { Assuntos } \\
\text { políticos }\end{array}$ & $\begin{array}{l}\text { Governo e } \\
\text { assuntos } \\
\text { políticos }\end{array}$ & $\begin{array}{l}\text { Contribuição para campanhas políticas } \\
\text { Prática anticorrupção e propinas } \\
\text { Prática de lobby e influência política }\end{array}$ \\
\hline & $\begin{array}{l}\text { Assuntos } \\
\text { jurídicos }\end{array}$ & $\begin{array}{l}\text { Respeito e } \\
\text { prática de } \\
\text { legislações }\end{array}$ & $\begin{array}{l}\text { Trabalhistas } \\
\text { Do consumidor } \\
\text { Ambientais } \\
\text { Comerciais } \\
\text { Fiscais }\end{array}$ \\
\hline
\end{tabular}




\section{Indicadores de performance social}

No modelo ECP-Social, considerou-se que a performance social não é determinística e, tampouco, linear. Além disso, os indicadores que permitem identificá-la referem-se às categorias de impacto sobre a.\& i. internos e externos (Quadro 3).

Segundo Leite (1998), a performance diz respeito aos resultados finais atingidos pelas empresas em função da estrutura e da conduta de mercado em que estão inseridas.

Quadro 3 - Categorias, dimensões e elementos de performance social.

\begin{tabular}{|c|c|c|c|}
\hline Categoria & Dimensão & Elemento & Critério de análise \\
\hline \multirow{7}{*}{$\begin{array}{l}\text { Performance } \\
\text { social }\end{array}$} & \multirow[b]{3}{*}{$\begin{array}{l}\text { Impacto } \\
\text { sobre os } \\
\text { a.\&i. } \\
\text { internos }\end{array}$} & $\begin{array}{l}\text { Retenção de } \\
\text { talentos }\end{array}$ & Índice de rotatividade de pessoal \\
\hline & & $\begin{array}{l}\text { Nível de satisfação } \\
\text { do trabalho }\end{array}$ & $\begin{array}{l}\text { Clima organizacional } \\
\text { Número de greves e paralisações } \\
\text { Evidência do comprometimento e envolvimento com a } \\
\text { empresa }\end{array}$ \\
\hline & & $\begin{array}{l}\text { Nível de segurança } \\
\text { e saúde } \\
\text { ocupacional }\end{array}$ & $\begin{array}{l}\text { Número de acidentes de trabalho, com afastamento } \\
\text { Número de acidentes de trabalho, com mortes } \\
\text { Número de acidentes de trabalho, com invalidez } \\
\text { Número de casos de doenças ocupacionais, com } \\
\text { afastamento } \\
\text { Número de casos de doenças ocupacionais, com morte } \\
\text { Número de casos de doenças ocupacionais, com invalidez } \\
\text { Número de horas/ano de treinamento/orientação em } \\
\text { segurança, saúde ocupacional e pessoal }\end{array}$ \\
\hline & \multirow{4}{*}{$\begin{array}{l}\text { Impacto } \\
\text { sobre os a. } \\
\& \text { i. } \\
\text { externos }\end{array}$} & $\begin{array}{l}\text { Envolvimento com } \\
\text { a comunidade }\end{array}$ & $\begin{array}{l}\text { Contribui com melhorias na infra-estrutura ou no } \\
\text { ambiente local que possam ser usufruídas pela } \\
\text { comunidade } \\
\text { Aumento da qualidade de vida da população: } \\
\begin{array}{ll}\text { - educação } & \text { - saúde }\end{array}\end{array}$ \\
\hline & & $\begin{array}{l}\text { Liderança e } \\
\text { influência social }\end{array}$ & $\begin{array}{l}\text { Possui membros de todos os níveis hierárquicos } \\
\text { envolvidos com projetos sociais } \\
\text { Participação e envolvimento em projetos sociais } \\
\text { governamentais }\end{array}$ \\
\hline & & $\begin{array}{l}\text { Imagem } \\
\text { organizacional }\end{array}$ & $\begin{array}{l}\text { Índice de rejeição da marca } \\
\text { Proporção de empregos ofertados X supridos } \\
\text { Grau de satisfação do cliente }\end{array}$ \\
\hline & & $\begin{array}{l}\text { Preocupação com } \\
\text { as futuras gerações }\end{array}$ & $\begin{array}{l}\text { Número de acidentes, com contaminação do solo } \\
\text { Número de acidentes, com contaminação da água } \\
\text { Número de acidentes, com contaminação do ar } \\
\text { Número de vítimas por consumo do produto } \\
\text { Número de vítimas por mau uso do } \\
\text { produto/embalagem/componentes } \\
\text { Número de acidentes com mortes } \\
\text { Número de acidentes com invalidez }\end{array}$ \\
\hline
\end{tabular}

Além disso, percebeu-se a necessidade de estabelecer uma ferramenta que torne operacionalizável o modelo ECP-Social, ou seja, que permita a identificação e avaliação do perfil de conduta social e da estrutura da indústria. 


\section{Ferramenta do modelo ECP-Social}

A ferramenta de avaliação do perfil de conduta social empresarial permite identificar as áreas em que a empresa possui maiores ou menores investimentos sociais, o que possibilita ao gestor direcionar estrategicamente as ações de responsabilidade social.

Por ser uma ferramenta que identifica os perfis de responsabilidade social, pode ser utilizada como benchmarking para a avaliação da competitividade social empresarial.

Para tanto, a ferramenta é composta por uma matriz de parâmetros, matriz de nível de conduta e matriz de perfil de responsabilidade social. A ferramenta foi constituída tendo como premissa básica que o perfil de conduta social é obtido por meio da definição do nível de conduta apresentado pela empresa no momento. Por sua vez, tal definição se dá a partir da identificação do seu comportamento frente aos elementos identificados no framework do modelo ECP-Social (Figura 3).

\section{Figuras 3 - Matrizes que compõem a ferramenta de avaliação do perfil de conduta social.}

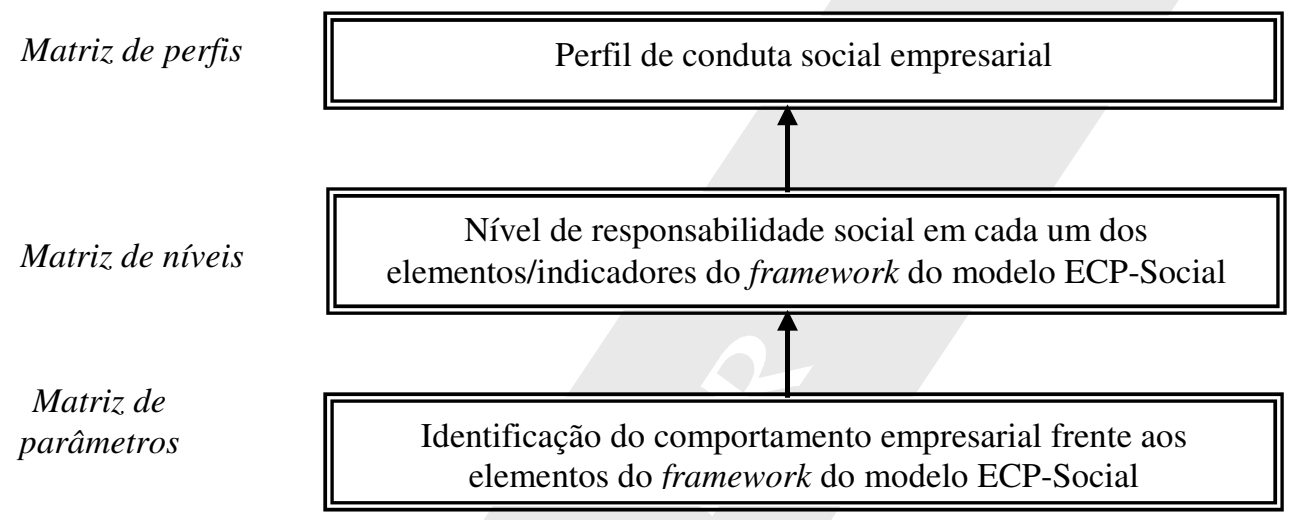

\section{Matriz de parâmetros}

A função da matriz de parâmetros é apontar o comportamento social da empresa frente a cada um dos critérios de análise da conduta social. Esses critérios são classificados em nível de conduta alta, moderada e fraca, uma vez que a empresa pode ter um comportamento social diferente para cada um dos dez elementos apresentados no framework do modelo ECP-Social e ainda uma postura diferente em cada um dos critérios de análise dos elementos do framework.

A primeira etapa do processo de avaliação do perfil de conduta social consiste no emprego da matriz de parâmetros, que é composta por todos os elementos identificados na categoria de conduta social do framework do modelo ECP-Social e classificados em três níveis (alto, moderado e fraco) de prática social empresarial,

Para se obter o nível de conduta social de cada uma das dimensões (administração geral, marketing e comunicação, e outros), foi necessário estabelecer pesos que os diferenciassem. Os pesos foram atribuídos da seguinte forma: no nível alto, cada resposta corresponde a 3 pontos; no nível moderado, a 2 pontos; e no nível fraco, a 1 ponto (Quadro 4). 


\section{Quadro 4-Pesos para a avaliação dos níveis de conduta social.}

\begin{tabular}{|l|l|l|l|}
\hline $\begin{array}{l}\text { Elementos } \\
\text { da categoria } \\
\text { "conduta social" }\end{array}$ & Fraca & Moderada & Alta \\
\hline & $\begin{array}{l}\text { Para cada resposta que se } \\
\text { enquadra neste nível, o peso } \\
\text { é 1. }\end{array}$ & $\begin{array}{l}\text { Para cada resposta que se } \\
\text { enquadra neste nível, o peso } \\
\text { é 2. }\end{array}$ & $\begin{array}{l}\text { Para cada resposta que se } \\
\text { enquadra neste nível, o } \\
\text { peso é 3. }\end{array}$ \\
\hline
\end{tabular}

Segundo este quadro, a empresa pode posicionar-se em níveis diferentes para responder a um elemento, haja vista que os elementos são compostos por vários critérios de análise. O somatório dos pontos apontará o nível de conduta social da empresa naquele elemento.

Para cada uma das dimensões, determinou-se um total máximo, moderado e mínimo de pontos que tem como objetivo identificar o nível de conduta social. Porém, para cada uma das dimensões de conduta social, o total de pontos varia, uma vez que algumas dimensões apresentam mais, ou menos, elementos e critérios de análise. Por exemplo, a dimensão "administração geral" apresenta um total de 51 pontos e um mínimo de 17 pontos, enquanto a dimensão de marketing e comunicação apresenta um máximo de 12 pontos e um mínimo de 04 pontos.

Caso algum dos critérios de análise apresentados não se enquadre à empresa, deve ser desconsiderado, nesse caso, será feita a diminuição do número máximo e mínimo de pontos, em 3 pontos, para o máximo, e 1 ponto, para o mínimo. Por exemplo, se a empresa não possui capital aberto e pertence a um único dono, o item "representação de acionistas minoritários" deve ser desconsiderado; portando, a pontuação deste item - que é de, no máximo, 06 - deve ser reduzida para, no máximo, 03. Assim também é possível que a empresa estabeleça outros indicadores, tendo em vista a melhoria do modelo ECP-Social.

A atribuição destes valores $(3,2,1)$ para cada um dos níveis tem como objetivo permitir a visualização do estágio em que se encontra a empresa dentro do nível de conduta social; portanto, os valores atribuídos à representação destes níveis servem para sinalizar tal posição. Assim, se estes números forem substituídos por quaisquer outros, desde que diferentes para cada nível, o objetivo desta matriz não será alterado.

Dado que as pontuações máxima e mínima de cada uma das funções gerenciais diferem uma da outra em escore final, é necessário homogeneizar as diferentes escalas, a partir da aplicação de uma fórmula: $y b-y a=m(x b-$ $x a)$.

Na sequiência, o modelo ECP-Social apresenta as matrizes de parâmetros de cada um dos elementos de conduta social. Para exemplificar, apresenta-se no Quadro 5 a matriz de parâmetros do elemento "pesquisa e desenvolvimento", estabelecidos com base em questionamentos referentes aos critérios de seleção de matériasprimas alternativas e da análise do ciclo de vida do produto, os quais determinam o nível de conduta social empresarial nesta dimensão.

\section{Quadro 5: Critérios de análise de conduta social: dimensão pesquisa e desenvolvimento}

\begin{tabular}{lll}
\hline & \multicolumn{2}{c}{ Critérios de análise da conduta social empresarial } \\
\hline Dimensão & Critério de análise & Questionamento para análise \\
\hline \multirow{2}{*}{$\begin{array}{l}\text { Pesquisa e } \\
\text { Desenvolvimento }\end{array}$} & $\begin{array}{l}\text { Seleção de matérias- } \\
\text { primas alternativas }\end{array}$ & $\begin{array}{l}\text { Qual o comportamento da empresa frente ao investimento } \\
\text { em matérias-primas/componentes alternativos? }\end{array}$ \\
\cline { 2 - 3 } & $\begin{array}{l}\text { Análise do ciclo de vida } \\
\text { do produto }\end{array}$ & $\begin{array}{l}\text { Qual o comportamento da empresa em relação à análise do } \\
\text { ciclo de vida do produto? }\end{array}$ \\
\hline
\end{tabular}

O nível de conduta social empresarial em pesquisa e desenvolvimento é identificado através da seguinte pontuação: o nível alto tem pontuação máxima de 06 pontos; o nível moderado, de 04 pontos; e o nível fraco, 
de 02 pontos. Na matriz de parâmetros representada pelo Quadro 6, a seguir, apresentam-se os comportamentos e cada um dos níveis de conduta social.

\section{Quadro 06: Matriz de parâmetros de conduta social da dimensão de pesquisa e desenvolvimento}

\begin{tabular}{|c|c|c|c|}
\hline \multicolumn{4}{|c|}{ Matriz de parâmetros de conduta social empresarial } \\
\hline $\begin{array}{ll}\text { Dimensão } & \text { Conduta Social } \\
\end{array}$ & Fraca (Peso 1,0) & Moderada (Peso 2,0) & Alta (Peso 3,0) \\
\hline \multirow[t]{2}{*}{ Pesquisa e desenvolvimento } & $\begin{array}{l}\text { A empresa não investe } \\
\text { em pesquisa de } \\
\text { matérias- } \\
\text { primas/componentes } \\
\text { alternativos. }\end{array}$ & $\begin{array}{l}\text { Investe } \\
\text { esporadicamente em } \\
\text { pesquisa de matéria- } \\
\text { prima/componentes } \\
\text { alternativos. }\end{array}$ & $\begin{array}{l}\text { Destina periodicamente } \\
\text { recursos para a pesquisa } \\
\text { de matérias-primas/ } \\
\text { componentes } \\
\text { alternativos, com } \\
\text { investimentos acima de } \\
1 \% \text { dos investimentos } \\
\text { totais. }\end{array}$ \\
\hline & $\begin{array}{l}\text { Não faz análise do ciclo } \\
\text { de vida do produto. }\end{array}$ & $\begin{array}{l}\text { Promove a análise do } \\
\text { ciclo de vida de } \\
\text { alguns produtos. }\end{array}$ & $\begin{array}{l}\text { Promove a análise do } \\
\text { ciclo de vida para cada } \\
\text { produto e implanta } \\
\text { programas de } \\
\text { gerenciamento dos } \\
\text { impactos ambientais e } \\
\text { sociais. }\end{array}$ \\
\hline
\end{tabular}

No nível alto de conduta social em pesquisa e desenvolvimento, a postura da empresa frente à investigação e ao emprego de matérias-primas e componentes alternativos é definida no planejamento estratégico e possui valor acima de $1 \%$ dos investimentos totais. Este percentual foi estabelecido com o objetivo de verificar a periodicidade do investimento nessa área. Não se tem a pretensão de se estipular um percentual "ideal", mas, sim, de incentivar uma periodicidade de investimento.

A empresa, neste nível de conduta, promove a análise do ciclo de vida de cada produto e implanta programas de gerenciamento dos impactos ambientais e sociais.

No nível de conduta social moderada em pesquisa e desenvolvimento, a empresa investe esporadicamente em matérias-primas e componentes alternativos e promove a análise do ciclo de vida de apenas alguns produtos.

Já a conduta social fraca em pesquisa e desenvolvimento é representada pela falta de investimento em matériasprimas alternativas e de análise do ciclo de vida dos produtos.

\section{Ferramenta de avaliação do perfil de conduta social}

A ferramenta de avaliação do perfil de conduta social tem como objetivo apresentar o resultado do processo anterior. Seu propósito é permitir a visualização do perfil de conduta social empresarial e auxiliar na tomada de decisão social, através da identificação do perfil social da empresa como um todo e também de cada uma das dimensões de análise.

Depois de se obterem os pesos relacionados à conduta social empresarial em cada uma das dimensões, estes são transferidos para a matriz de perfil de conduta social, que tem como representação gráfica uma flor (Figura 4). Nesta flor, estão contidas as dez dimensões da categoria de conduta social, apontadas como framework do modelo ECP-Social e representadas graficamente por pétalas da flor.

Optou-se por caracterizar o nível de conduta social alto com a cor verde (situação positiva); a moderada, com a cor amarela (requer atenção); e a fraca, com a cor vermelha (menos apropriada). Esta definição de cores tem como propósito facilitar a visualização da conduta social da empresa em determinado elemento. 
Considerando-se que os elementos, identificados na matriz de parâmetros, possuem pesos 1, para fraca; 2, para moderada; e 3, para alta, cada uma das pétalas demonstrará o comportamento empresarial em cada uma das dimensões. Assim, por exemplo, a empresa pode ter um comportamento de nível alto em meio ambiente, moderado em pesquisa e desenvolvimento, e fraco em manufatura.

Portanto, o preenchimento da matriz de avaliação do perfil de conduta social se dá a partir do total de pontos obtidos em cada uma das dimensões no exercício da matriz de parâmetros.

\section{Figura 4-Matrizes de perfil de conduta social.}

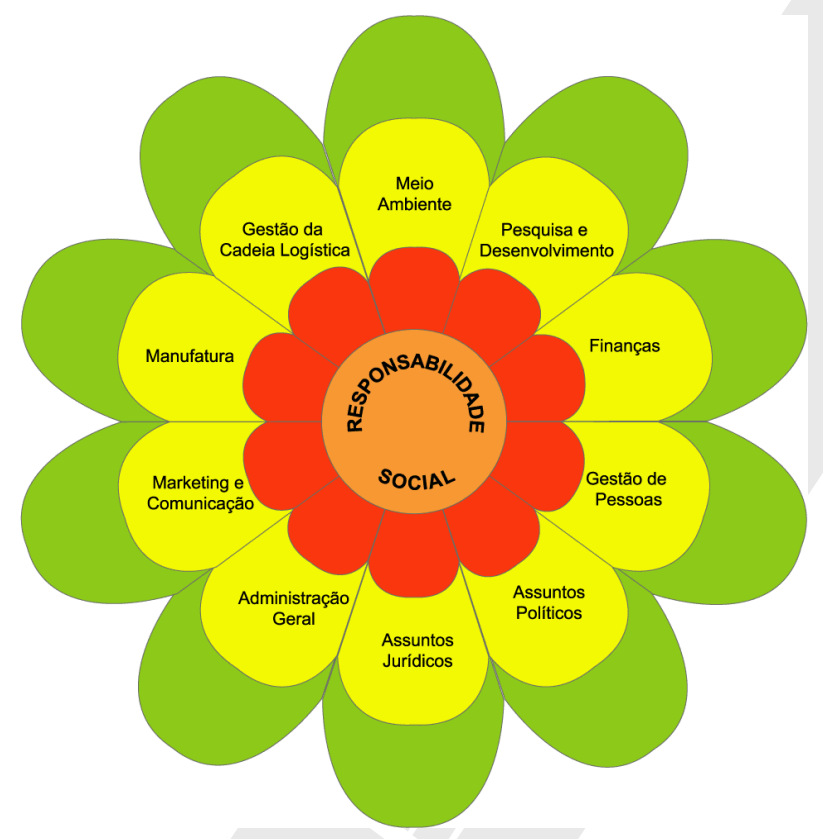

Observa-se que cada uma das pétalas da flor está composta de uma régua de medição que expressa os valores máximos, moderados e mínimos (Figura 5), conforme o valor total de cada dimensão, que varia de acordo com a quantidade de indicadores de análise. Portanto, o exercício da matriz de nível de conduta social ocorre da seguinte forma: (1) identifica-se o total de pontos obtidos para cada uma das dimensões da categoria de conduta social através da matriz de parâmetros; (2) posiciona-se, em cada uma das dimensões (pétalas) da matriz de níveis (flor), o somatório obtido anteriormente; e, (3) traça-se uma linha interligando as dimensões (pétalas).

Figura 5 - Régua de medição da matriz de perfil de conduta social.

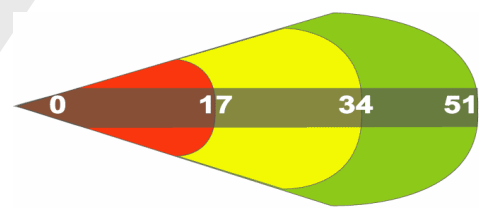

Administração Geral

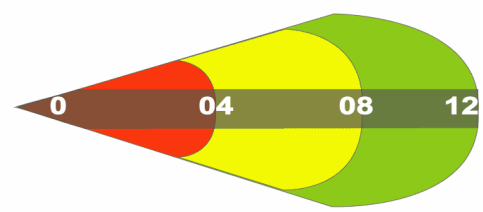

Marketing e Comunicação 
Através dos procedimentos anteriores, encontrar-se-á, como resultado, uma "estrela" sobre a flor, conforme apresentado a seguir na Figura 6.

\section{Figura 6 - Exemplo da aplicação da matriz de perfil de conduta social.}

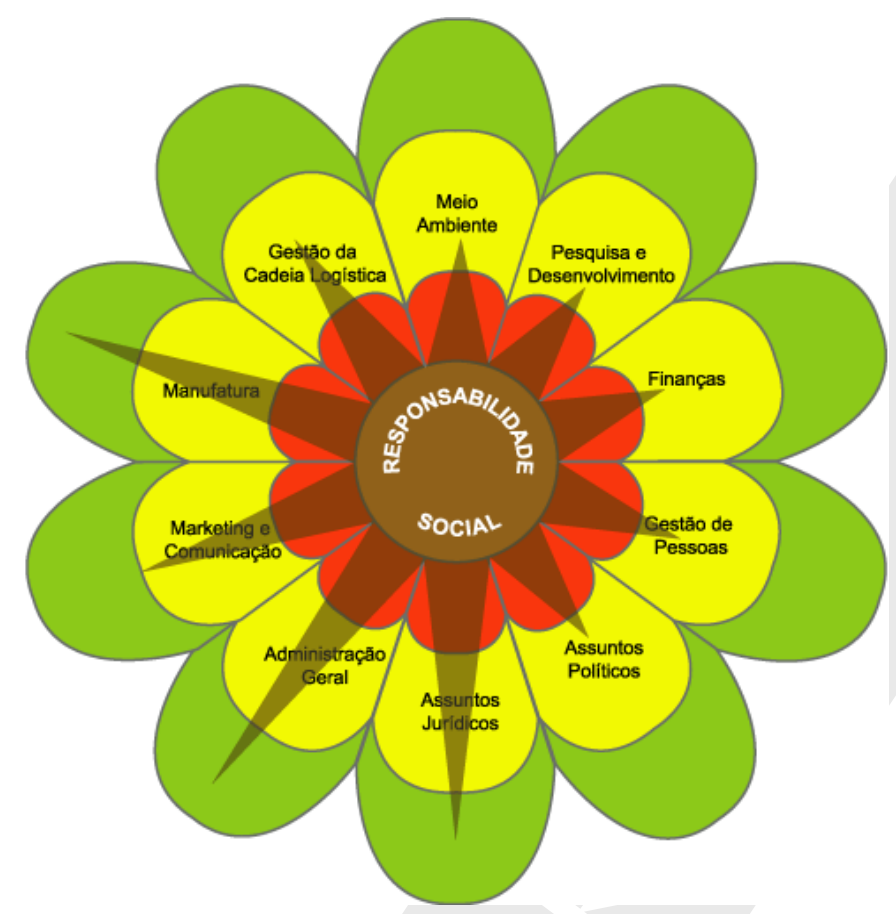

Como resultado do exercício da matriz de parâmetros e, posteriormente, da matriz de nível de conduta social, espera-se que desta última se obtenha um formato de estrela, demonstrando as dimensões nas quais a empresa está atuando com maior e menor intensidade, o que permitirá que o gestor defina as áreas de maior atenção e investimento.

Para a definição do perfil de conduta social da empresa, estabeleceu-se que aquele nível no qual consta o maior número de posicionamentos dentro de uma mesma esfera é que representa a conduta empresarial. Por exemplo: se a empresa possui mais da metade dos níveis de perfis, 5 ou mais, dentro da esfera verde, ela apresenta uma conduta alta. Por outro lado, se a empresa identificou 3 níveis na esfera amarela, 3 níveis na esfera verde e 4 níveis na esfera vermelha, sua conduta empresarial é fraca.

Em caso de empate, 5 dimensões em um nível e 5 em outro, o critério de desempate é a posição da empresa no nível em que se encontra a dimensão de administração geral. Tal escolha se dá em função de que este é o nível que apresenta como critérios de análise a ética e os valores da empresa, que são os responsáveis pelas diretrizes de todos os demais comportamentos empresariais. A partir disso, é possível avaliar a conduta social empresarial e confrontá-la com a estrutura do setor, a qual permitirá estabelecer os perfis de responsabilidade social empresarial.

\section{Perfil de responsabilidade social empresarial}

A matriz de identificação do perfil de conduta social baseou-se na matriz de correlação entre conduta ambiental e pressão sobre a estrutura da indústria do modelo ECP-Ambiental (ABREU, 2001), que apresenta dois níveis de pressão sobre a indústria e três níveis de perfil de conduta. No modelo ECP-Social, o perfil social da empresa é obtido através da confrontação entre a estrutura da indústria e o perfil de conduta social da empresa, em uma matriz que apresenta três níveis de pressão da estrutura da indústria (alta, moderada e baixa) e três níveis de conduta social (alta, moderada e fraca) (Figura 7). 
Figura 7 - Matrizes de perfil social empresarial.

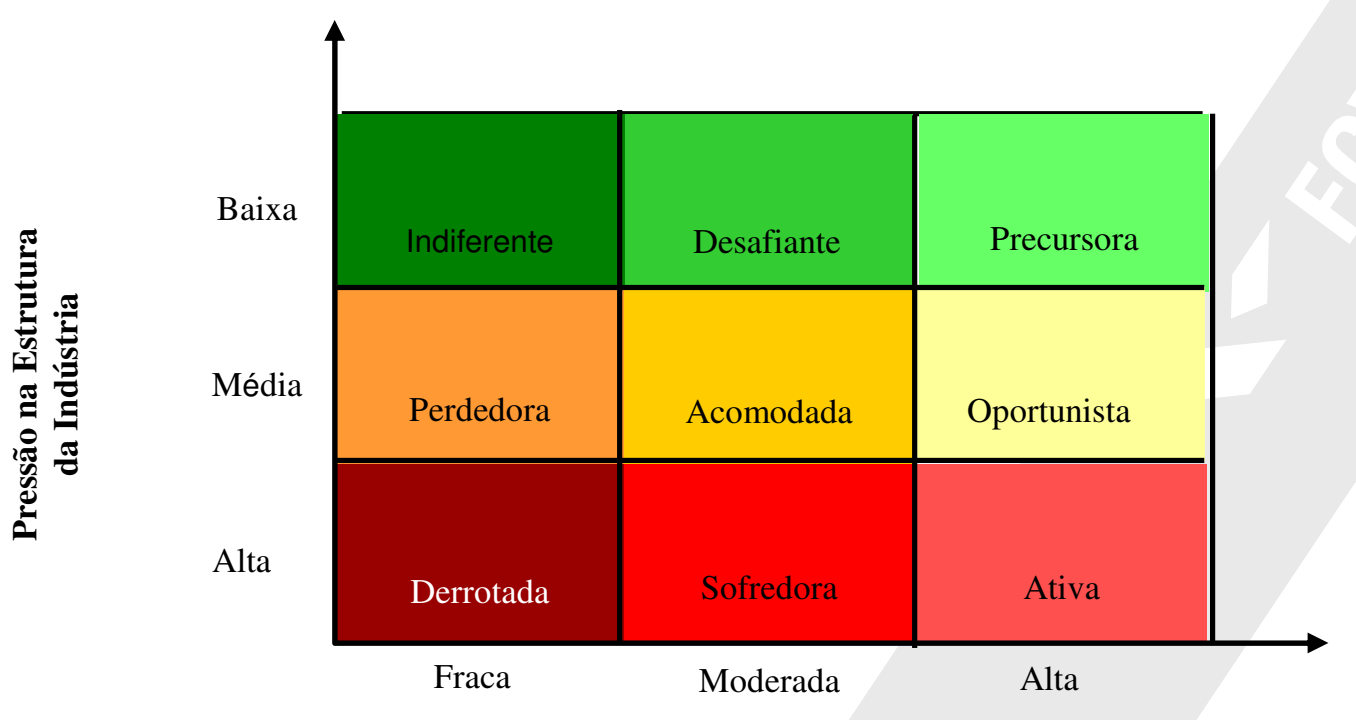

Perfil de Conduta

\section{Conclusão}

Dessa forma, pode-se dizer que o modelo criado contempla indicadores que capturam opiniões internas e externas, uma vez que apresenta as relações de causa e efeito entre os afetados e interessados pelos processos empresariais, permitindo, assim, uma avaliação da performance social mais eficaz.

A competência de integrar o aspecto social ao processo de tomada de decisão oferece uma vantagem competitiva valiosa para a empresa, o que pode ser alcançado criando-se um ambiente propício para o tratamento destas questões associadas às questões econômicas e ambientais.

O modelo aponta, portanto, o gerenciamento das variáveis sociais e a necessidade de inserir os conceitos de responsabilidade social na tomada de decisão estratégica, para que os impactos dos processos gerenciais sejam tratados de forma sistêmica e equilibrada.

Não se tem, no entanto, a pretensão de criar padrões absolutos de responsabilidade social, mas formas analíticas para contextualizar e solucionar os problemas, tendo em vista que não se podem padronizar preferências, valores, em função de aspectos culturais ou organizacionais.

Considera-se que os resultados do Modelo ECP-Social apresentam o demonstrativo do desempenho social atual e a possibilidade de projeção do desempenho social futuro da empresa.

Ressaltam-se as seguintes contribuições do modelo apresentado:

- a avaliação do perfil de conduta social através da ferramenta apresentada auxilia a tomada de decisão para o gerenciamento do impacto social;

- a ferramenta de avaliação do perfil social da empresa, uma vez que torna operacionalizável o framework do modelo. Acredita-se que ela supre as lacunas existentes nos modelos atuais e permite uma tomada de decisão eficiente, que auxiliará a empresa a garantir a sua sustentabilidade;

- a sua concepção não excluiu nenhuma das funções gerenciais, pois isso significaria uma visão míope do espectro da responsabilidade social de uma empresa. 
Como limitantes o modelo apresenta os seguintes pontos:

- não analisa as correlações entre o porte da empresa e o seu comportamento;

- os indicadores da dimensão "meio ambiente" foram estabelecidos levando-se em consideração que, na aplicação individual do modelo ECP-Social, os aspectos ambientais não devem ser excluídos, porém, a expansão desta dimensão é uma limitante do modelo à cadeia logística;

- os indicadores apresentados foram constituídos tendo em conta os valores sociais brasileiros. Os resultados e as interpretações consideraram valores sociais vigentes, portanto, para a aplicação do modelo, deve-se observar a contextualização histórica, geográfica e temporal.

O desenho do modelo e da ferramenta atrai a atenção dos empresários, principalmente em função da fácil operacionalização, visualização dos resultados e projeção de metas de melhorias. Por isso, acredita-se que o modelo ECP-Social contribui para a ampliação da prática da responsabilidade social empresarial, desmistificando o uso de modelos acadêmicos relativos a este tema, tendo como perspectiva a popularização da prática no meio empresarial.

A partir da construção do modelo ECP-Social, é possível concluir que:

- existem formas de ação social, isto é, há gestão social nas empresas, portanto, é possível estabelecer os perfis sócio-empresariais, além de agrupar as empresas de um setor segundo um perfil de comportamento;

- a aplicação do modelo ECP-Social contribui para que as empresas avaliem seu posicionamento estratégico atual (resultado da matriz de perfil social) e para que definam qual a posição que desejam ocupar. Além disso, considerando que todo o posicionamento é relativo, o modelo induz as empresas a estabelecerem comparações com os seus principais competidores, ou entre suas unidades de negócios;

- o posicionamento é dinâmico, o que significa que a ocorrência de eventos significativos, denominados de choques, pode mudar o posicionamento social. Por exemplo, acidentes com consumidores de um produto que provoquem um novo comportamento da sociedade podem fazer com que uma empresa passe de um posicionamento de "acomodada" para o de "sofredora";

- empresas pertencentes ao mesmo setor industrial, portanto, sujeitas a características sociais similares, podem apresentar níveis diferentes de comportamento social e, conseqüentemente, diferentes perfis;

- os aspectos dinâmicos do modelo são percebidos pelas diferentes formas de absorção e de adaptação das pressões exercidas pela estrutura sobre as práticas sociais das empresas, com reflexos na sua performance.

Assim, conclui-se que o modelo ECP- Social configura-se como uma proposta para diminuir o grau de incerteza na tomada de decisão da gestão social. O seu alcance se configura a partir das relações entre as variáveis de causa e efeito, apontando as causas do desempenho ruim e os "elos" que deveriam ser trabalhados, o que permite estabelecer metas de melhoria para a promoção de negócios sustentáveis. 


\section{Referências}

ABREU, Mônica Cavalcanti Sá de. Modelo de avaliação da estratégia ambiental: Uma ferramenta para a tomada de decisão. 2001. Tese (Doutorado em Engenharia de Produção) - Programa de Pós-Graduação em Engenharia de Produção, Universidade Federal de Santa Catarina, Florianópolis.

CARROLL, Archie B. A three-dimensional conceptual model of corporate performance. Academy of Management Review, v. 4, n. 4, p. $497-$ 505, 1979.

Corporate social responsibility: evolution of a definitional construct. Business \& Society, v. 38, n. 3, p. 268-295, Sept. 1999.

CARROLL, Archie B.; BuchholTz, Ann K. Business \& society: Ethics and Stakeholder Management. 5. ed. Ohio: Thomsson South-western, 2003.

IBASE - Instituto Brasileiro de Análises Sociais e Econômicas. Disponível em: <www.ibase.org.br>. Acesso em: ago. 2004.

LEITE, A. L. S. Concentração e desempenho competitivo no complexo industrial de papel e celulose. 1998. Dissertação (Mestrado em Engenharia de Produção) - Programa de Pós-Graduação em Engenharia de Produção, Universidade Federal de Santa Catarina, Florianópolis.

MITCHELL, Ronald L.; AGLE, Bradley R.; WOOD, Donna J. Towards a theory of stakeholder identification and salience: defining the principle of who and what really counts. Academy of Management Review, v. 4, n. 22, p. 853-886, Oct. 1997.

Revista Exame. Guia da Boa Cidadania Corporativa. São Paulo: Editora Abril, 26 dez. 2003. Edição especial.

SCHERER, F. M.; ROSS, D. Industrial Market Structure and Economic Performance. Boston: Houghton Mifflin Co.,1990.

Silva, Edna Lúcia da; MENEZES, Estela M. Metodologia da pesquisa e elaboração de dissertação. 3. ed. rev. atual. Florianópolis: Laboratório de Ensino a Distância da UFSC, 2001.

TAKALA, Tuomo. From social responsibility to environmental responsibility: Changes in the finnish business discourse from 1970 to 1995. Eletronical Journal of Business and Organization Ethics Network, v. 01, n. 01, 1996. Disponivel em: <http://ejbo.jyu.fi/index.cgi?page=archives>. Acesso em: Feb. 2003.

SWANSON, Diane L. Addressing a theoretical problem by reorienting the corporate social performance model. Academy of Management Review, v. 20, n. 1, p. 43-94, 1995.

Toward an integrative theory of business and society: A research strategy for corporate social performance. Academy of Management Review, v. 24, n. 3, p. 506-521, 1999.

WARTICK, Steven L.; COCHRAN, Philip L. The evolution of the corporate social performance model. Academy of Management Review, v. 10, n. 4, p. 758-769, 1985.

WOOD, Donna J. Corporate social performance revisited. Academy of Management Review, v. 16, n. 4, p. 691-718, 1991. 